\title{
Effect of DEA in Membrane Gas Absorption System Using Polymeric Flat Sheet Membrane
}

\author{
A. L. Ahmad ${ }^{1 *}$, A. R. Sunarti ${ }^{2}$, K. T. Lee ${ }^{3}$ \& W. J. N. Fernando ${ }^{4}$ \\ ${ }^{1,2,3 \& 4}$ School of Chemical Engineering, Engineering Campus, Universiti Sains Malaysia, 14300 Nibong Tebal, \\ Pulau Pinang, Malaysia \\ ${ }^{2}$ Faculty of Chemical Engineering and Natural Resources, Universiti Malaysia Pahang, 25000 Kuantan, Pahang, \\ Malaysia
}

\begin{abstract}
The objective of this study was to investigate the potential process of the removal of carbon dioxide $\left(\mathrm{CO}_{2}\right)$ from flue gases by using developed membrane gas absorption system. The experiments were performed in membrane gas absorption system consisted $0.45 \mu \mathrm{m}$ pore size microporous polyvinylidenefluoride (PVDF) flat sheet membrane. Diethanolamine (DEA) solution was employed as the liquid absorbent. The operating parameters such as the gas and liquid flow rate were setup at $100 \mathrm{~cm}^{3} / \mathrm{min}$ and $25 \mathrm{~cm}^{3} / \mathrm{min}$ and liquid absorbent was at room temperature. The effect of DEA concentration was studied with variation in range $1 \mathrm{M}$ to $5 \mathrm{M}$. In addition, the experiments were carried out with $20 \%, 40 \%$ and $100 \%$ gas ratio $\mathrm{CO}_{2}$ to $\mathrm{N}_{2}$. The results show that hydrophobic polymeric membranes such as PVDF can be efficiently used for gas absorption with optimized concentration of DEA.
\end{abstract}

Keywords: Membrane gas absorption, $\mathrm{CO}_{2}$ removal, DEA, polymeric membrane

\subsection{INTRODUCTION}

Membranes have become an established technology for carbon dioxide $\left(\mathrm{CO}_{2}\right)$ removal since their first use in this application in 1981. Initial acceptance was slow and limited to smaller streams, mostly because of the economic risks involved in treating larger streams, but also because many process design parameters were largely unknown. A further factor was the general downturn in the oil and gas industry in the 1980s. The multiple benefits of membrane technology promised by early innovators have since been proven in a wide variety of installations in many locations around the world, and vendors of traditional $\mathrm{CO}_{2}$ removal technologies have been quick to acquire or develop membrane-based processes to supplement their older processing routes. In some cases, the most economical

* Correspondence to: A. L. Ahmad (email: chlatif@eng.usm.my) approach is to combine membranes with existing technologies or use membranes to debottleneck existing solvent-based plants. Currently, the only commercially viable membranes used for $\mathrm{CO}_{2}$ removal are polymer based, for example, cellulose acetate, polyimides, polyamides, polysulfone, polycarbonates, and polyetherimide. Polyimide has some potential in certain $\mathrm{CO}_{2}$ removal applications, but it has not received sufficient testing to be used in large applications.

Flue gas is a gas released to the atmosphere via a flue and quite often refers to the combustion exhaust gas produced at power plants. Its composition generally depends on what is being burned, but usually consist of mostly carbon dioxide $\left(\mathrm{CO}_{2}\right)$ and water vapor as well as nitrogen $\left(\mathrm{N}_{2}\right)$ and excess oxygen. It also contains a small percentage of pollutants such as particulate matter, carbon monoxide ( $\mathrm{CO}$ ), nitrogen oxides (NOx) and sulfur oxides (SOx). Lately, the removal of $\mathrm{CO}_{2}$ from flue gases has received 
intense attention due to the properties of $\mathrm{CO}_{2}$. The $\mathrm{CO}_{2}$ has long been identified as one of the main green house gasses present in the atmosphere (other green house gases are such as methane and ozone). The accumulation of $\mathrm{CO}_{2}$ has been well associated with the recent increase in global temperature. A wide variety of acid gas removal technologies are available. They include cryogenic processes; adsorption processes, such as pressure swing adsorption (PSA), thermal swing adsorption (TSA) and iron sponge as well membranes. The conventional method to remove $\mathrm{CO}_{2}$ is using gas absorption. In gas absorption processes, the gases mixtures are usually dispersed and in direct contact with liquid in absorption devices such as packed or plate columns. Absorption process in these contact devices has many shortcomings like emulsions, foaming, unloading and flooding [1]. An alternative technology that overcomes these disadvantages and also offers more interfacial area than the conventional approaches is a nondispersive contactor via a microporous membrane or better known as membrane gas absorption (MGA). In MGA system, the fluids to be contacted flow on the opposite side of the membrane, and the gas-liquid interface forms at the mouth of each membrane pore. The available contact area remains undisturbed even at a high or low flow rate because the two fluid flows are independent. Because the absorbent liquid flows on one side and the gas flows on the other side of the membrane, this method is useful in applications where the required solvent/feed ratio is very high or very low [2]. In terms of liquid absorbents, several of them have been studied experimentally. These including pure water and aqueous solutions of $\mathrm{NaOH}, \mathrm{KOH}$, amine and amino acid salts [3]. Wang investigated the pure $\mathrm{CO}_{2}$ absorbed in diethanolamine (DEA), 2-amino-2methyl-1-propanol (AMP) and methyldiethanoamine (MDEA) aqueous solutions [4]. Dindore tested the process of $\mathrm{CO}_{2}$ absorbed in propylene carbonate at high gas pressure (1-20 bars) [5]. For Kvaerner, MGA had been used for the removal of acid gases from natural gas and flue gases from conventional gas turbines [3]. However, to achieve high $\mathrm{CO}_{2}$ absorption rates, higher reactive absorbents are widely used, such as sodium hydroxide $(\mathrm{NaOH})$ and monoethanolamine (MEA).

The objective of this paper is to emphasis on effect of DEA concentration in designed MGA system comprising hydrophobic microporous polyvinylidenefluoride (PVDF) flat sheet membrane. It is discussed how the MGA system potential to remove the $\mathrm{CO}_{2}$ in $\mathrm{CO}_{2} / \mathrm{N}_{2}$ mixture.

\subsection{THEORY}

The impact of DEA solutions on the membrane surface would be representative for the cases of primary and secondary amines. It is a widely used absorbent with two ethanol groups attached to a nitrogen atom. The reaction of DEA $\left(\mathrm{R}_{1} \mathrm{R}_{2} \mathrm{NH}\right)$ with dissolved $\mathrm{CO}_{2}$ is generally described by the zwitterion mechanism in a two-step sequence, i.e. the fist step is the formation of intermediate zwitterions [6]:

$$
\mathrm{CO}_{2}+\mathrm{R}_{1} \mathrm{R}_{2} \mathrm{NH} \underset{k_{1}}{\stackrel{k_{2}}{\rightleftarrows}} \mathrm{R}_{1} \mathrm{R}_{2} \mathrm{NH}+\mathrm{CO}_{2}^{-}
$$

Then the zwitterion is deprotonated by the bases present in the solution, forming a carbamate ion and a protonated base:

$$
\begin{aligned}
\mathrm{R}_{1} \mathrm{R}_{2} \mathrm{NH} & +\mathrm{CO}_{2}^{-}+\mathrm{R}_{1} \mathrm{R}_{2} \mathrm{NH} \stackrel{K_{a m}}{\rightleftarrows} \mathrm{R}_{1} \mathrm{R}_{2} \mathrm{NCO}_{2}^{-} \\
& +\mathrm{R}_{1} \mathrm{R}_{2} \mathrm{NH}_{2}^{+} \\
\mathrm{R}_{1} \mathrm{R}_{2} \mathrm{NH} & +\mathrm{CO}_{2}^{-}+\mathrm{H}_{2} \mathrm{O} \stackrel{\mathrm{K}_{\mathrm{H} 2 \mathrm{O}}}{\longleftarrow} \mathrm{R}_{1} \mathrm{R}_{2} \mathrm{NCO}_{2}^{-} \\
& +\mathrm{H}_{3} \mathrm{O}^{+} \\
\mathrm{R}_{1} \mathrm{R}_{2} \mathrm{NH} & +\mathrm{CO}_{2}^{-}+\mathrm{OH}^{-} \stackrel{\mathrm{K}_{\mathrm{OH}}}{\longleftarrow} \mathrm{R}_{1} \mathrm{R}_{2} \mathrm{NCO}_{2}^{-} \\
& +\mathrm{H}_{2} \mathrm{O}
\end{aligned}
$$

Thus, the components contained in a DEA aqueous solution after reacting with $\mathrm{CO}_{2}$ include $\mathrm{CO}_{2}, \mathrm{R}_{1} \mathrm{R}_{2} \mathrm{NH}, \mathrm{R}_{1} \mathrm{R}_{2} \mathrm{NCO}_{2}^{-}$and $\mathrm{R}_{1} \mathrm{R}_{2} \mathrm{NH}_{2}{ }^{+}$.

\subsection{METHODS}

The hydrophobic microporous polyvinylidenefluoride (PVDF) flat sheet membrane used in this experiment were purchased from Millipore Asia LTD. The membrane pore size is $0.45 \mu \mathrm{m}$ and 


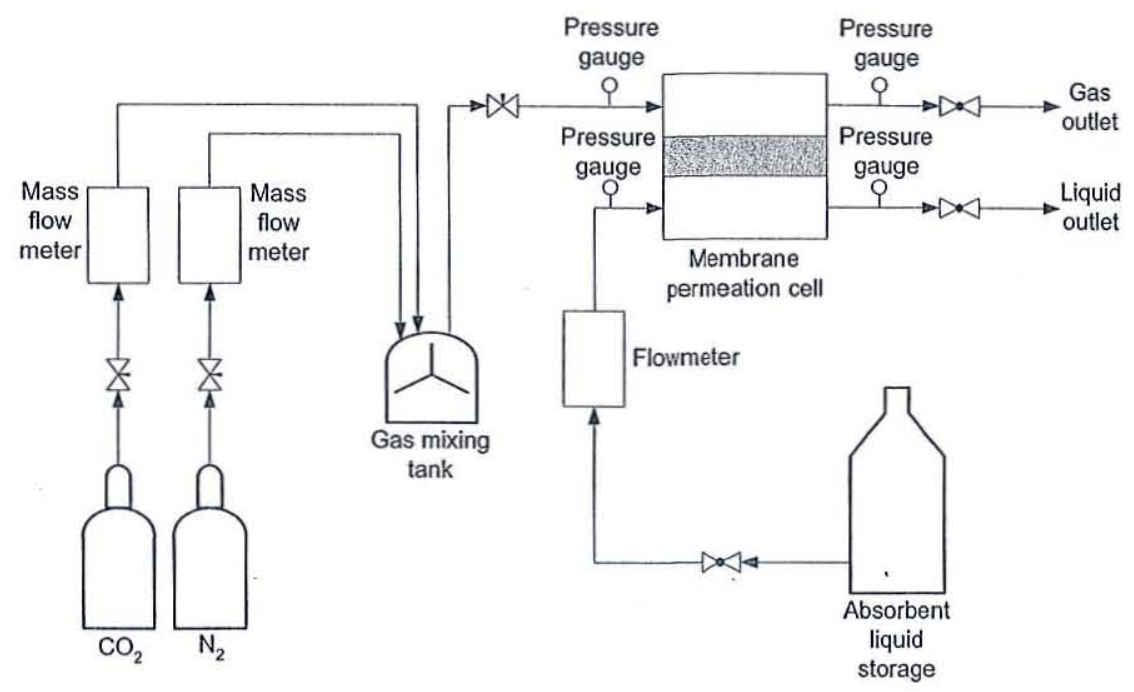

Figure 1 Schematic diagrams of membrane gas absorption system

the membrane porosity is 0.75 . A $99 \%$ grade Diethanolamine (DEA) purchased from Sigma Aldrich (M) Sdn. Bhd. was mixed with deionized water, respectively to prepare aqueous liquid absorbents with desired concentrations. The experimental setup is schematically shown in Figure 1.

Pure $\mathrm{CO}_{2}$ and pure $\mathrm{N}_{2}$ were mixed with a volume ratio of $20: 80,40: 60$ or $100: 0$, which is in composition range of flue gas, was used as the feed gas while DEA aqueous solution were employed as liquid absorbents. In the experiment, the flow rate of the feed of the feed gas supplied from compressed gas cylinder was adjusted and controlled by Aalborg mass flow controllers, and then it was fed through up side of the membrane module. The inlet and outlet gas volume flow rate were measured by a bubble soap meter. The pressure gauges were used to indicate the inlet and outlet pressure of the gas and liquid. When $\mathrm{CO}_{2} / \mathrm{N}_{2}$ mixture was used as the feed gas, Gas Chromatography (Perkin Elmer, TCD) was used to analyze the inlet and outlet gases compositions. All the data were collected after experiment had been operated for $30 \mathrm{~min}$ to ensure the system to reach the steady state. The results of each run were averaged from five times of sampling. The system and operating parameters which influence the process performance such as $\mathrm{CO}_{2}$ concen- tration in the feed, and DEA concentration were varied based on the experimental design. Either pure or mixed gas flow rate were fixed at $100 \mathrm{~cm}^{3}$ / min while liquid absorbent flow rate was fixed at $25 \mathrm{~cm}^{3} / \mathrm{min} .1,2,3,4$ and $5 \mathrm{M}$ of DEA were studied. All of the experiments were performed at the room temperature; therefore, the gas phase temperature in this work was approximately at $30^{\circ} \mathrm{C}$.

\subsection{RESULTS AND DISCUSSIONS}

The $\mathrm{CO}_{2}$ removal efficiency $(\eta)$ and mass transfer rate $\left(\mathrm{J}_{\mathrm{CO} 2}\right)$ were used to describe the running conditions. $\eta$ and $\mathrm{J}_{\mathrm{CO} 2}$ are determined by the following equations $[7,8,9,10]$ :

$$
\begin{gathered}
\eta=\frac{\mathrm{Q}_{\text {in }} \times \mathrm{Q}_{\text {in }}-\mathrm{Q}_{\text {out }} \times \mathrm{C}_{\text {out }}}{\mathrm{Q}_{\text {out }} \times \mathrm{C}_{\text {in }}} \\
\mathrm{J}_{\mathrm{CO} 2}=\frac{\left(\mathrm{Q}_{\text {in }} \times \mathrm{Q}_{\text {in }}-\mathrm{Q}_{\text {out }} \times \mathrm{C}_{\text {out }}\right) \times 273.15 \times 1000}{22.4 \times T_{\mathrm{g}} \times \mathrm{S}}
\end{gathered}
$$

where $\eta$ is the $\mathrm{CO}_{2}$ removal efficiency, \%; $\mathrm{J}_{\mathrm{CO} 2}$ is the mass transfer rate of $\mathrm{CO}_{2}, \mathrm{~mol} /\left(\mathrm{m}^{2} \mathrm{~s}\right) ; \mathrm{Q}_{\text {in }}$ and $\mathrm{Q}_{\text {out }}$ are the gas flow rates at the inlet and the outlet of the membrane, respectively, $\mathrm{cm}^{3} / \mathrm{s}$; $\mathrm{C}_{\text {in }}$ and $\mathrm{C}_{\text {out }}$ are $\mathrm{CO}_{2}$ concentrations in the gas 
phase at the inlet and the outlet of the membrane, respectively, $\mathrm{cm}^{3} ; T_{g}$ is the real temperature of the flue gas, $\mathrm{K} ; \mathrm{S}$ is the gas-liquid interfacial area, $\mathrm{m}^{2}$.

\subsection{Effect of Wetting Criteria of DEA on PVDF Membrane}

Diethanolamine (DEA) was chosen in this study, as it is a commercial absorbent with reasonable $\mathrm{CO}_{2}$ absorption capacity and moderate corrosiveness. Figure 2 shows the experimental results of $\mathrm{CO}_{2}$ absorption by $2 \mathrm{M}$ aqueous solution of DEA in the membrane gas absorption system for about $12 \mathrm{~h}$.

For the DEA absorbent, the membrane gas absorption system was successfully operated for about $12 \mathrm{~h}$, maintaining a $\mathrm{CO}_{2}$ removal efficiency of about $90 \%$. It was clearly indicated that $2 \mathrm{M}$ aqueous of DEA solution can not wet the PVDF membrane in the long-term operation of about $12 \mathrm{~h}$. It was well known that increasing the concentration of the active species in the solvent will enhance the mass transfer as. well. With respect to economics, solvent circulation rate is one of the most important factors in determining the economics of a gas treating process using chemical solvent. So, the relatively higher concentration of DEA could be selected to absorb

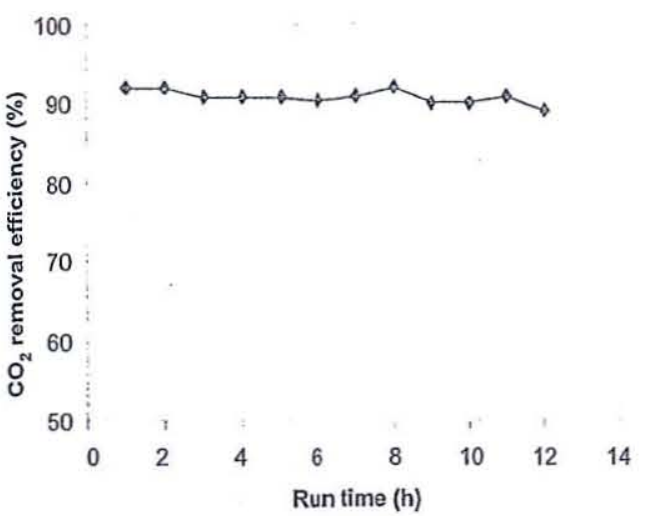

Figure 2 Long-term performance of the PVDF membrane gas absorption system over $12 \mathrm{~h}$ at ambient temperature $\left(\mathrm{CO}_{2} / \mathrm{N}_{2}-\right.$ DEA system, P gas: 1 bar)

$\mathrm{CO}_{2}$ from flue gas in order to enhance the mass transfer [3] and reduce the solvent circulation rate.

\subsection{Effect of DEA Concentration on Mass Transfer Rate of $\mathrm{CO}_{2}$}

The dependence of mass transfer rate of $\mathrm{CO}_{2}$ on initial absorbent concentration was illustrated in Figure 3 . It was clearly shown that the mass

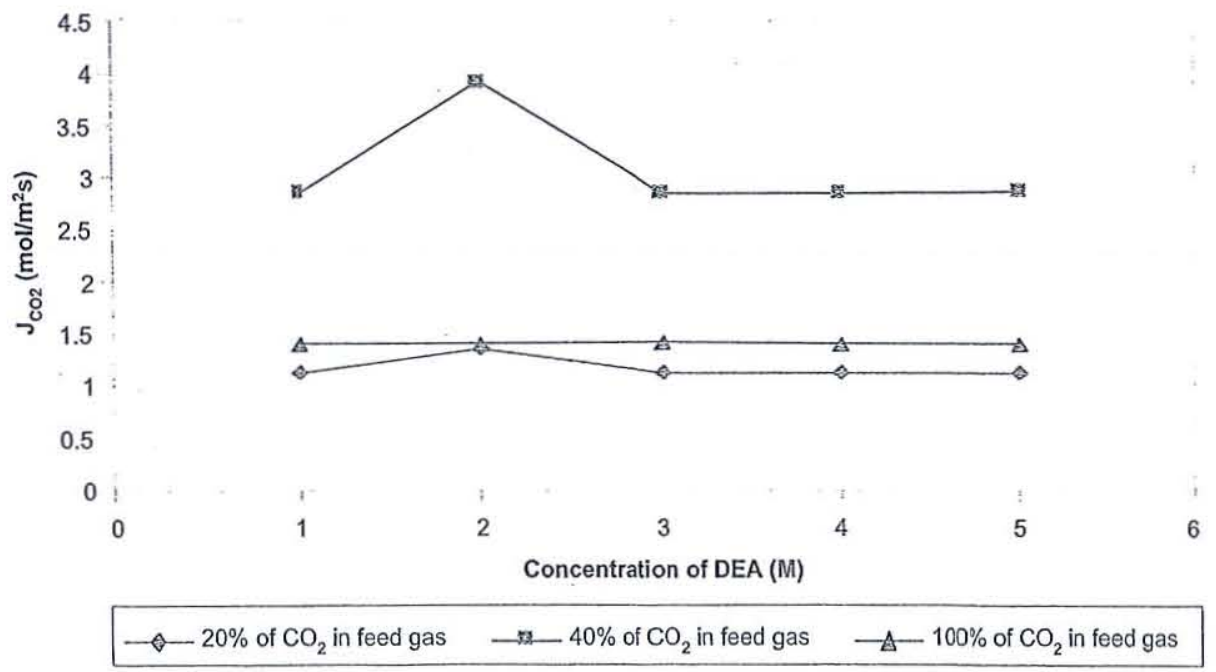

Figure 3 Effect of the liquid absorbent concentration on the mass transfer rate of $\mathrm{CO}_{2}$ (gas flow rate: $100 \mathrm{ml} / \mathrm{s}$, liquid flow rate: $25 \mathrm{ml} / \mathrm{s}$, liquid absorbent temperature: $303.15 \mathrm{~K}$ ) 
transfer rate generally increased at $2 \mathrm{M}$ of the absorbent concentration and going to unchange at the end. These trends are similar with research were done by Kumar et al. [8] using potassium taurate (PT), S. Yan et al. [9] using potassium glycinate (PG), Kim and Yang [11] using 2amino-2-methyl-1-propanol (AMP) and Wang et al. [4] using methyldiethanolamine (MDEA), monoethanolamine (MEA) and AMP with different concentration, respectively. These was because that the active component absorbing $\mathrm{CO}_{2}$ in the liquid boundary layer increased with the absorbent concentration, which results in higher $\mathrm{CO}_{2}$ solubility and lower liquid flow rate. However, in this case, liquid flow rate was fixed at $25 \mathrm{~cm}^{3} / \mathrm{min}$.

As far as the higher $\mathrm{CO}_{2}$ removal efficiency and the lower liquid flow rate were concerned, it is worthwhile to increase the initial absorbent concentration. However, the absorbent concentration can not be elevated without limitation when using DEA as the absorbent. Other than that, Figure 3 also shows that the mass transfer rate shown the highest reading around $3.9 \mathrm{~mol} /$ $\mathrm{m}^{2} \mathrm{~s}$ when the DEA concentration at $2 \mathrm{M}$ for $40 \%$ of $\mathrm{CO}_{2}$ in feed gas. Meanwhile, mass transfer for $20 \%$ of $\mathrm{CO}_{2}$ in feed gas also increased with $2 \mathrm{M}$ DEA. It was because $\mathrm{CO}_{2}$ absorption was enhanced by the chemical reaction. However, a compromise has to be taken among higher mass transfer rate of $\mathrm{CO}_{2}$, the potential of membrane wetting problem and crystallization prevention when using DEA as the liquid absorbent.

\subsection{CONCLUSION}

Experiments for PVDF flat sheet membrane were performed extensively to determine the performance of aqueous DEA solution in the removal of $\mathrm{CO}_{2}$ from flue gas when some key operating factors were fixed. It was clearly seen from the results that the performance of $\mathrm{CO}_{2}$ absorption using $2 \mathrm{M}$ of was always superior to $40 \%$ of $\mathrm{CO}_{2}$ in feed gas compared to $20 \%$ and $100 \%$ of $\mathrm{CO}_{2}$ in feed gas under the same operating conditions. Far from that, long-term performance tests using $2 \mathrm{M}$ of DEA solution as the liquid absorbent shown that the DEA aqueous solution was suitable to be applied to the PVDF microporous membrane gas absorption because the DEA aqueous solution can provide a higher separation performance and the $\mathrm{CO}_{2}$ flux was kept almost unchanged over 12 hours of operation especially for flat sheet membrane module.

\section{ACKNOWLEDGEMENTS}

This work was supported by the Science Fund from the Ministry of Science and Technology, Malaysia (6013350) and Exxon Mobil Short Term Grant (6050137),

\section{REFERENCES}

[1] Bessarabov, D.G., E.P. Jacobs, R.D. Sanderson, and I.N. Beckam. 1996. Use of Nonporous Polymeric Flat-Sheet GasSeparation Membranes in a MembraneLiquid Contactor: Experimental Studies. J. Membr. Sci. 113: 275-284.

[2] Wang, R., H.Y. Zhang, P.H.M. Feron, and D.T. Liang. 2005. Influence of Membrane Wetting on $\mathrm{CO}_{2}$ Capture in Microporous Hollow Fiber Membrane Contactors. Sep. Purif. Technol. 46: 33-40.

[3] Li, J.L., and B.H. Chen. 2005. Review of $\mathrm{CO}_{2}$ Absorption using Chemical Solvents in Hollow Fiber Membrane Contactors. Sep. \& Purif. Tech. 41: 109-122.

[4] Wang, R., D.F. Li, and D.T. Liang. 2004. Modelling of $\mathrm{CO}_{2}$ Capture by Three Typical Amine Solutions in Hollow Fiber Membrane Contactors. Chem. Eng. Process. 43: 849-856.

[5] Dindore, V. Y., D.F. Brilman, P.H.M. Feron, and G.F. Versteeg. 2004. $\mathrm{CO}_{2}$ Absorption at Elevated Pressures using a Hollow Fiber Membrane Contactor. J. Membr. Sci. 235: 99-109.

[6] Wang, R., D.F. Li, C. Zhou, M. Liu, and D.T. Liang. 2004. A Impact of DEA Solutions with and without $\mathrm{CO}_{2}$ Loading on Porous Polypropylene Membranes Intended for Use as Contactors. J. Membr. Sci. 229: 147157. 
[7] Kumar, P.S., J.A. Hogendoorn, P.H.M. Feron, and G.F. Versteeg. 2004. New Absorption Liquids for the Removal of $\mathrm{CO}_{2}$ from Dilute Gas Streams using Membrane Contactors. Chem. Eng. Sci. 57: 1639-1651.

[8] Yeon, S.-H., K.-S. Lee, B. Sea, Y.-I. Park, and K.-H. Lee. 2005. Application of Pilotscale Membrane Contactor Hybrid System for Removal of Carbon Dioxide from Flue Gas. J. Membr. Sci. 257: 156-160.

[9] Yan, S.P., M.X. Fang, W.F. Zhang, S.Y.Wang, Z.K. Xu, Z.Y. Luo, and K.F. Cen. 2007.
Experimental Study on the Separation of $\mathrm{CO}_{2}$ from Flue Gas using Hollow Fiber Membrane Contactors without Wetting. Fuel Process Technol. 88: 501-511.

[10] Atchariyawut, S., R. Jiraratananon, and R. Wang. 2007. Separation of $\mathrm{CO}_{2}$ from $\mathrm{CH}_{4}$ by using Gas-LiquidMembrane Contacting Process. J. Membr. Sci. 304: 163-172.

[11] Herzog, H.J. 2007. What Future for Carbon Capture and Sequestration. Environ. Sci. Technol. 35: 148A-153A. 